\title{
Diabetes Risk Assessment among Adult Men in Baghdad City Using Finnish Diabetes Risk Score (FINDRISC)
}

\author{
Mayasah A. Sadiq, Alaa A.Salih* \\ Assistant Professor, Department of Family and Community Medicine, College of Medicine, University of \\ Mustansiriyah, Baghdad, Iraq
}

*Corresponding Author: Alaa A. Salih, Assistant Professor, Department of Family and Community Medicine, College of Medicine, University of Mustansiriyah, Baghdad, Iraq.

Email:draasalih@yahoo.com

\begin{abstract}
Background: Different risk models also known as risk scores have been developed to detect type 2 diabetic cases. Identifying individuals with undiagnosed T2DM can be an important approach in preventing or delaying complications. In this research we are using the Finnish Diabetes Risk Score (FINDRISC) questionnaire which is a screening tool to estimate risk of type 2 diabetes to assess the risk and for giving health education and preventive measures for those with highest risk score.
\end{abstract}

Method: A descriptive cross-sectional study was carried out, Study subjects enrolled 456 male participants from outpatient clinic of Al-Yarmouk teaching hospital in Baghdad in period of 2 months. Adult men aged from 18 years and above were recruited using a Finnish Diabetic Risk Score as questionnaire form.

Results: The results estimates $32 \%$ have a low risk to develop the disease, 34\% have a slightly elevated risk, $18 \%$ have a moderate risk, 14\% have a high risk and 2\% have a very high risk. 55\% were below 45 years, $42 \%$ were overweight, $60 \%$ of them were active and daily fruit and vegetables consumers, $34 \%$ have first degree diabetic relative.

Conclusion: Very small percentage (2\%) have a very high risk while $14 \%$ have a high risk to develop DM, Almost two thirds do daily physical exercise and eat fruit and vegetables every day. One third of them had weight circumference below $94 \mathrm{~cm}$, about $80 \%$ have no history of hypertension.

Keywords: FINDRISC, Diabetes, men.

\section{INTRODUCTION}

Diabetes mellitus is a group of metabolic diseases characterized by hyperglycemia (high blood sugar) resulting from defects in the secretion of insulin, its action, or both. Many pathogenic processes are involved in the development of diabetes. These range from autoimmune destruction of the $\beta$-cells of the pancreas with consequent insulin deficiency to abnormalities that lead to resistance to the action of insulin. [1]

There are two main types of diabetes, insulindependent diabetes mellitus (type 1 diabetes mellitus, T1DM) and non-insulin-dependent diabetes mellitus (type 2 diabetes mellitus, T2DM). T2DM is the most common form of diabetes mellitus (DM); it is about $90 \%$ to $95 \%$ of all diabetic patients and is expected to increase to 439 million by 2030. [2]
Type-2 diabetes is a major, non-communicable disease with increasing global prevalence. Type2 diabetes results when the body does not make enough insulin or the body cannot use the insulin it produces. [3]

Individuals with type $2 \mathrm{DM}$ are at a significantly higher risk for coronary heart disease, peripheral vascular disease and stroke, as well as microvascular complications that affect various organs including the eyes, kidneys and nerves. [4]

Iraq is considered as a developing country. Studies mainly concentrating on anthropometric association with diabetes. Cut-off values of body mass index (BMI) for association with type 2 diabetes mellitus and hypertension were $25.4 \mathrm{~kg} / \mathrm{m}^{2}$ and $24.9 \mathrm{~kg} / \mathrm{m}^{2}$, respectively, in men which is consistent with the current 
definitions of overweight (BMI $\geq 25 \mathrm{~kg} / \mathrm{m}^{2}$ ) recommended by World Health Organization (WHO). [5]

The increased prevalence of type II diabetes can be attributed to many factors such as ageing population and rising incidence of obesity, besides other factors. The Middle East is predicted to have the greatest rate of rise, and as a country of the Middle-East, Iraq is affected by this epidemic. [6]

Certain lifestyle factors are known to be important to the development of type 2 DM. These are physical inactivity, sedentary lifestyle, obesity, cigarette smoking and alcoholism. Sedentary life style is one of the most important risk factors for type $2 \mathrm{DM}$, sitting for long periods of time (excluding sleeping) is known as a sedentary lifestyle and is associated with an increased risk of Type 2 diabetes. [7]

Researchers have shown a strong link between having a large waist circumference and an increased risk of developing T2 DM.A large study found that overweight people with a large waist (defined in this study as over 40 inches $/ 102 \mathrm{~cm}$ for men and over 34.5 inches $/ 88 \mathrm{~cm}$ for women) had a similar risk of developing diabetes to those who are clinically obese, this relationship was particularly strong in women. [8]

Although diet and nutrition are widely believed to play an important part in the development of Type 2 diabetes mellitus. Dietary recommendations to prevent Type II diabetes should focus more on the quality of fat and carbohydrate in the diet than quantity alone, in addition to balancing total energy consumption with expenditure to avoid overweight and obesity. [9]

Hypertension is common among diabetic patients, with the prevalence depending on type and duration of diabetes, age, sex, race, BMI, and other factors. Furthermore, hypertension is considered as a strong risk factor for atherosclerotic cardiovascular disease (ASCVD), ASCVD is the leading cause of morbidity and mortality for diabetic patients. According to studies, antihypertensive therapy reduces ASCVD events in people with diabetes. [10]
A family history of diabetes is a strong risk factor for the development of type 2 diabetes. This factor is likely to be mediated, in part, by both genetic and shared environmental components amongst family members, but the exact factors concerning this increase in risk are not well understood. [11]

Identifying individuals with undiagnosed T2DM can be an important approach in preventing or delaying T2DM complications. Different risk models, also known as risk scores, have been developed to detect T2DM cases. Some of them are useful to detect undiagnosed (prevalent) T2DM cases, whereas other ones predict the development of new (incident) T2DM cases.

In this research we are using The Finnish Diabetes Risk Score (FINDRISC) questionnaire which is a screening tool to estimate risk of type 2 diabetes. It takes into account the usual clinical characteristics, such as age, body mass index (BMI), waist circumference (WC), physical activity, and dietary consumption of fruits, vegetables, and berries, use of antihypertensive medication, history of high blood glucose, and family history of diabetes. FINDRISC can be a suitable tool to predict metabolic syndrome in a high-risk population and to identify undetected metabolic syndrome in clinical practice. [12]

Aims:

- To assess the risk for type 2 Diabetes mellitus by using Finnish Diabetes Risk Score (FINDRISC) questionnaire.

- To give health education to each participant about risk for future diabetes measures of prevention.

\section{SubJeCTS AND Method}

\subsection{Study Design}

The study was designed as a descriptive cross sectional study.

\subsection{Study Subjects and Data Collection}

Study subjects enrolled a convenient sample from outpatient clinic of Al-Yarmouk teaching hospital in Baghdad in period from February 2019 to March 2019. Adult men aged from 18 years and above were recruited. 
The questionnaire used is, titled as "Type 2 Diabetes Risk Assessment Form". The Finnish Diabetes Risk Score (FINDRISC) was designed by Finnish diabetes association, which is one of the most frequently used instruments for assessing the risk of DM. After taking permission from each individual and explaining to them the purpose of study.

\section{Each participant should have the following measures:}

- Measure the weight in $\mathrm{Kg}$ and the height in $\mathrm{cm}$

Weight was measured by a scale after shoes and heavy clothes were taken off. Height was measured by tape measure in centimeters with patients standing up against wall after footwear taken off.

Then we calculated the BMI by apply the formula of $\mathrm{BMI}=$ weight in $\mathrm{kg}$ / (height in meter ${ }^{2}$ )

- Measure the waist circumference in $\mathrm{cm}$

Waist circumference was measured by tape measure by wrapping it in midway between highest point of iliac crest and the bottom of ribcage after removing clothes from this line.
Total Risk score of each participant was classified according to (FINDRISC) questionnaire

- Score Lower than 7: estimated 1 in 100 will develop disease (1\%)

- 7-11 slightly elevated: estimated 1 in 25 will develop disease (4\%)

- 12-14 Moderate: estimated 1 in 6 will develop disease (17\%)

- 15-20 High: estimated 1 in 3 will develop disease $(33 \%)$

- Higher than 20 very high: estimated 1 in 2 will develop disease (50\%)

Each study participant was made aware of his FINDRISC score, those having scores $\geq 12$ were given health education about risk, and preventive measures for diabetes and participants were advised to carryout blood sugar tests wherever necessary.

The data entry was done using Excel; percentages were calculated and designed as suitable graph and table.

\section{Results}

Total number is 456 participants

Table1. Risk classification distribution according to variables

\begin{tabular}{|c|c|c|c|c|c|c|c|}
\hline Variable & group & \begin{tabular}{|l} 
Low risk \\
No $(\%)$
\end{tabular} & $\begin{array}{l}\text { Slight risk } \\
\text { No }(\%)\end{array}$ & \begin{tabular}{|l|} 
Moderate \\
risk \\
No $(\%)$ \\
\end{tabular} & \begin{tabular}{|l|l} 
High \\
risk \\
No (\%) \\
\end{tabular} & $\begin{array}{l}\text { Very high } \\
\text { risk } \\
\text { No }(\%) \\
\end{array}$ & Total \\
\hline \multirow[t]{4}{*}{ Age } & $<45$ & $123(84 \%)$ & $80(51.6 \%)$ & $27(33.75 \%)$ & $15(23 \%)$ & $0(0 \%)$ & $245(55 \%)$ \\
\hline & $45-54$ & $14(9.6 \%)$ & $3220.6 \%)$ & $21(26.2 \%)$ & $16(24.6 \%)$ & $3(27 \%)$ & $86(19 \%)$ \\
\hline & $55-65$ & $7(4.8 \%)$ & $29(18.7 \%)$ & $22(27.5 \%)$ & $21(32.3 \%)$ & $3(27 \%)$ & $82(18 \%)$ \\
\hline & $>65$ & $1(0.68 \%)$ & $14(9 \%)$ & $10(12.5 \%)$ & $13(20 \%)$ & $5(45 \%)$ & $43(9 \%)$ \\
\hline \multirow[t]{3}{*}{ BMI } & $<25 \mathrm{~kg} / \mathrm{m}^{2}$ & $94(64.8 \%)$ & $38(24.5 \%)$ & $4(5 \%)$ & $4(6 \%)$ & $0(0 \%)$ & $140(31 \%)$ \\
\hline & $25-30 \mathrm{~kg} / \mathrm{m}^{2}$ & $49(33.79 \%)$ & $87(56.1 \%)$ & $33(41.2 \%)$ & $18(27.6 \%)$ & $5(45 \%)$ & $192(42 \%)$ \\
\hline & $>30 \mathrm{~kg} / \mathrm{m}^{2}$ & $2(1.37 \%)$ & $30(19.35 \%)$ & $43(53.75 \%)$ & $43(66 \%)$ & $6(54 \%)$ & $124(27 \%)$ \\
\hline \multirow[t]{3}{*}{ WC } & $<94 \mathrm{~cm}$ & $120(82.75 \%)$ & $39(25.1 \%)$ & $3(3.75 \%)$ & $4(6.1 \%)$ & $0(0 \%)$ & $166(36.4 \%)$ \\
\hline & $94-102 \mathrm{~cm}$ & $19(13.1 \%)$ & $75(48.38 \%)$ & $24(30 \%)$ & $13(20 \%)$ & $2(18 \%)$ & $133(29.2 \%)$ \\
\hline & $>102 \mathrm{~cm}$ & $6(4.1 \%)$ & $41(26.45 \%)$ & $53(66.25 \%)$ & $48(73.8 \%)$ & $9(81 \%)$ & $157(34.4 \%)$ \\
\hline \multirow{2}{*}{$\begin{array}{l}\text { Physical } \\
\text { activity }\end{array}$} & Active & $110(75.8 \%)$ & $90(58 \%)$ & $43(53.75 \%)$ & $29(44.6 \%)$ & $4(36.36 \%)$ & $276(60.5 \%)$ \\
\hline & Inactive & $35(24.13 \%)$ & $65(42 \%)$ & $37(46.25 \%)$ & $36(55.4 \%)$ & $7(63.63 \%)$ & $180(39.6 \%)$ \\
\hline \multirow{2}{*}{ Healthy Diet } & Yes & $86(59.31 \%)$ & $100(64.5 \%)$ & $50(62.5 \%)$ & $33(50.67 \%)$ & $6(54.54 \%)$ & $275(60 \%)$ \\
\hline & No & $59(40.68 \%)$ & $55(35.4 \%)$ & $30(37.5 \%)$ & $32(49.23 \%)$ & $5(45.45 \%)$ & $181(40 \%)$ \\
\hline \multirow{2}{*}{$\begin{array}{l}\text { Antihyper- } \\
\text { tensive drugs }\end{array}$} & Yes & $5(3.44 \%)$ & $2414.4 \%)$ & $18(22.5 \%)$ & $35(53.84 \%)$ & $7(63.63 \%)$ & $89(20 \%)$ \\
\hline & No & $140(96.55 \%)$ & $131(84.51 \%)$ & $62(77.5 \%)$ & $30(46.15 \%)$ & $4(36.36 \%)$ & $367(80 \%)$ \\
\hline \multirow{2}{*}{$\begin{array}{l}\text { High Blood } \\
\text { sugar test }\end{array}$} & Yes & $0(0 \%)$ & $13(8.38 \%)$ & $9(11.2 \%)$ & $24(37 \%)$ & $11(100 \%)$ & $57(12.5 \%)$ \\
\hline & No & $145(100 \%)$ & $142(91.16 \%)$ & $71(88.8 \%)$ & $41(63 \%)$ & $0(0 \%)$ & $399(87.5 \%)$ \\
\hline \multirow{3}{*}{\begin{tabular}{|l|} 
DM \\
family \\
history
\end{tabular}} & No & $74(51 \%)$ & $61(39 \%)$ & $20(25 \%)$ & $3(4.6 \%)$ & $0(0 \%)$ & $166(36.4 \%)$ \\
\hline & $1^{\text {st }}$ degree & $45(31 \%)$ & $40(26 \%)$ & $19(24 \%)$ & $19(29.6 \%)$ & $2(18 \%)$ & $133(29.2 \%)$ \\
\hline & $2^{\text {nd }}$ degree & $26(18 \%)$ & $54(35 \%)$ & $41(51 \%)$ & $43(66 \%)$ & $9(81 \%)$ & $157(34.4 \%)$ \\
\hline
\end{tabular}




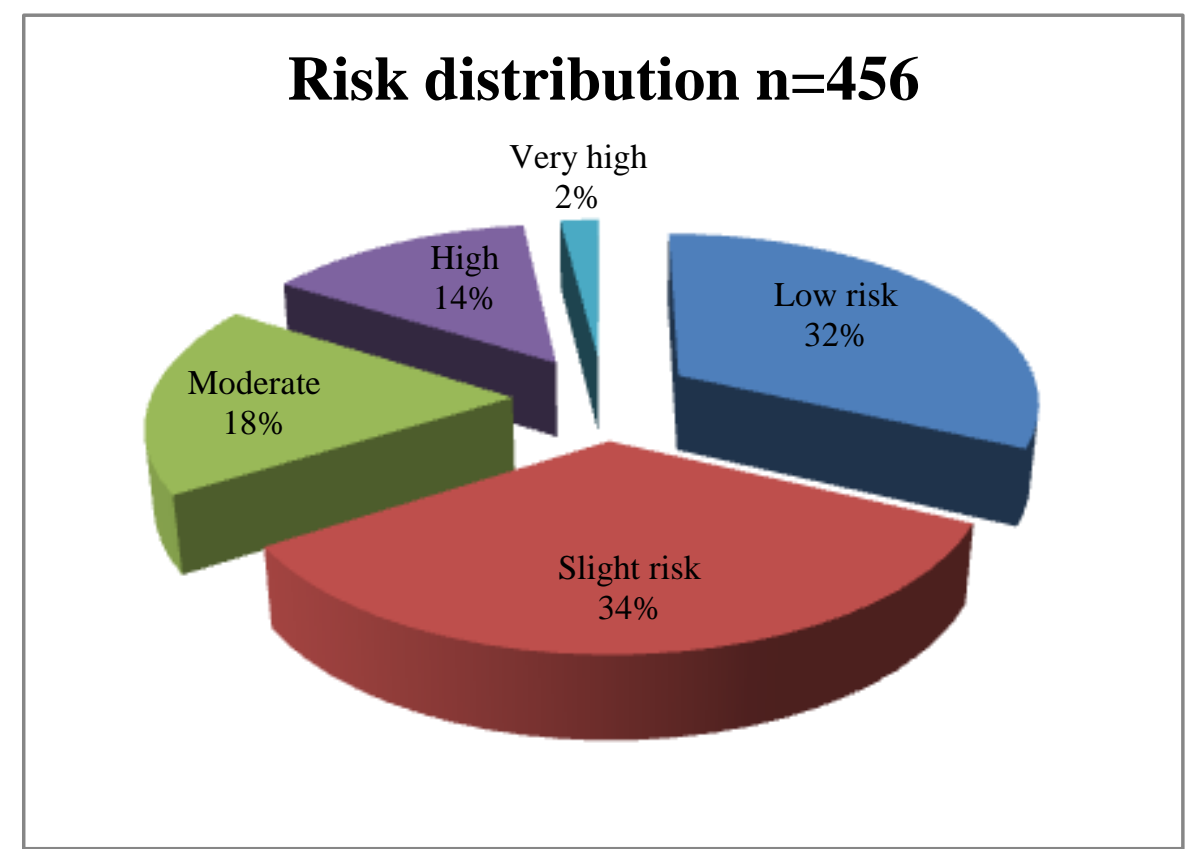

Figure1. Pie chart: Risk classification distribution

\section{DisCuSSION}

By using Finnish diabetic risk score for estimating the probability of a person to develop diabetes within the next years among adult males who lives in Baghdad. FINDRISC has been widely adopted as a low-cost screening tool in many European countries, USA, India, Oman, Jordan and KSA to enable early identification of individual risk of type 2 diabetes. [13]

Our sample is of 456 adult males who live in Baghdad with undiagnosed DM. the results estimates $32 \%$ have a low risk to develop the disease, $34 \%$ have a slightly elevated risk, $18 \%$ have a moderate risk, $14 \%$ have a high risk and $2 \%$ have a very high risk to develop DM (Pie graph).

Almost half of the adults (55\%) in our sample were below the age of 45 years. most of the cases $(84 \%)$ who are at low risk are under the age of 45 years, while only $1 \%$ are above the age of 64 and $(45 \%)$ who are at a very high risk are above the age of 64 years of age (Shown in the table).

Recently, the BMI had been linked to the nutritional status and ethnic group, so they now consider the normal BMI for Asian population is between (18.5-22.9) $\mathrm{kg} \backslash \mathrm{m}^{2}$, overweight is between (23-24.9) $\mathrm{kg} \backslash \mathrm{m}^{2}$, while obesity is more than $25 \mathrm{~kg}^{2}$. [14]
As table the shows, the majority of the low risk cases $\left(64.8 \%\right.$ ) have a BMI below the $25 \mathrm{Kg} \backslash \mathrm{m}^{2}$, most of the cases $(66 \%)$ who are at high risk are obese, while the cases who are at very high risk $45 \%$ of them are overweight and 54\% are obese. $42 \%$ of all cases are overweight and $27 \%$ of all cases are obese while male obesity prevalence among Iraqi adult according to WHO IN 2016 is $30.4 \%$ and estimates that Iraq is the $8^{\text {th }}$ Arabic country highest in obesity(Shown in the table). [15]

The low risk case has $75.8 \%$ a physical activity for $30 \mathrm{~min}$ per day while $24.1 \%$ have a less physical activity. While $63.6 \%$ of the very high risk cases have no daily physical activity.

$60.5 \%$ of all the cases have a daily physical activity and $39.6 \%$ have no daily physical activity (Shown in the table) While a research in Oman estimates that $44.1 \%$ of Omani adults have a daily physical activity and $55.9 \%$ have no daily physical activity. [15]

While a research in Oman in 2013 where the majority of the adults $90.3 \%$ were below 45 years, and the majority of them $87.1 \%$ were men estimates that $26.9 \%$ of them are overweight and $18.3 \%$ are obese .[16]

The majority $(82.7 \%)$ of the low risk cases have a waist circumference lower than 94 while only $4.1 \%$ have a waist circumference more than 102 . Most of Moderate risk cases $(66.25 \%)$ have a 
waist circumference above $102 \mathrm{~cm}$. And most of the high risk cases $(73.8 \%)$ are also above 102 $\mathrm{cm}$, and cases that are of very high risk (81\%) of them also above $102 \mathrm{~cm}, 34.4 \%$ of all cases have a high WC (Shown in the table). This indicates that abdominal obesity is a problem that is common and prevalent among over weight and obese males. While a research in Oman estimates that $45.4 \%$ of Omani adults have a high WC. [16]

Around $(81 \%)$ of very high risk cases and $(66 \%)$ of high risk cases have a first degree relatives with DM, while only $18 \%$ of the low risk cases had a first degree relatives with DM , family history is one of the most important non modifiable risk factors for developing DM .

In general $63.6 \%$ of all cases had a family history of DM, of these 34\% Had a first degree relatives with DM (Shown in the table) While a study in Oman estimates that $31.2 \%$ of Omani adult population had a family history of DM, of these $11.8 \%$ had a first degree relatives with DM. [16]

About $40.6 \%$ of the low risk cases does not eat vegetables every day and Almost half of the cases that are at high risk (49.2\%) and very high risk $(45.4 \%)$ does not eat vegetables every. $40 \%$ of all cases does not eat vegetables every day (table 2) while a research in Jordan in 2017 among young student population ((with significant change in age (18-25), BMI (ONLY $31.3 \%$ are overweight and obese), WC (only $6.1 \%$ have a WC over than 102), $42.6 \%$ of them have no daily physical activity, only $1.7 \%$ are taking antihypertensive medication, and $50.1 \%$ have a second degree relatives with DM and $24.8 \%$ have a first degree relatives with DM)), estimates that $43.5 \%$ of young males does not eat vegetables every day. [17]

This indicates that Increase in WC and high BMI among Iraqi adult males were related to poor lifestyle, physical activity (poor insulin sensitivity, hyperinsulinaemia, dyslipidemia) and low consumption of vegetables and fruits among Iraqi adult males.

None of the low risk cases had a high blood glucose before while all of the very high risk case had a high blood glucose at a time, $63 \%$ of the high risk cases had a history of elevated blood sugar in their lives, $12.5 \%$ of all cases had a history of an elevated blood sugar (Shown in the table), while a research in Jordan among young population estimate $4.1 \%$ of young males had an elevated blood sugar in their lives [4] while in Oman $26.9 \%$ of Omani adults have a history of an elevated blood sugar [17]

As the table shows, More than the half of cases that are at high risk $(53.8 \%)$ and very high risk $(63.6 \%)$ are taking medication for hypertension while only $3.4 \%$ of the low risk cases are taking medication for HT, $20 \%$ of all our cases are taking medication for HT while a research in India in 2017 estimates that $54.89 \%$ of the moderate risk cases, $85.21 \%$ of the high risk cases and $93.61 \%$ of the very high risk cases are taking medication for hypertension, as a total $23.33 \%$ of them are taking medication for HT (with significant change in gender $(54 \%$ were females), age (48.84\% of the low risk cases were between 55_64 years and only $23.9 \%$ are under 45 years while $20.3 \%$ of the very high risk cases are above 64 years), BMI (20.6\% are overweight and $4.7 \%$ are obese) physical activity (only $3.5 \%$ have less daily physical activity), and only $10 \%$ of them have a first degree family history of DM, only $12.6 \%$ have a WC more than 102). [18]

\section{CONCLUSiON}

- Results estimates $32 \%$ have a low risk to develop the disease while $2 \%$ have a very high.

- Almost two thirds of adults included in our study do daily physical exercise best for $30 \mathrm{~min}$ and eat fruit and vegetables every day.

- One third of them had WC below $94 \mathrm{~cm}$, and a first degree relative who have DM in

- The majority (about $80 \%$ ) have no history of hypertension.

\section{RECOMMENDATION}

- The FINDRISC questionnaire is a simple, reliable, noninvasive and valuable screening tool to identify individuals who are at risk of developing type $2 \mathrm{DM}$ and individuals with asymptomatic undiagnosed DM. 
- Obesity, high waist circumference, dietary pattern and physical activity are factors that play a substantial role in the development of T2DM.

- Alteration of these risk factors will significantly reduce the risk assessment score.

- People with high risk should be encouraged to modify their life style through maintaining ideal body weight and consuming healthy food.

- They also should be encouraged to do physical activity.

- People at high age group or have hypertension or a family history of DM should be educated to attend PHC centers, hospitals and clinics to do periodic checks for blood sugar and blood pressures.

- Public education by the health care providers for early detection and prevention of complication of diabetes is a priority.

- The ministry of health is also urged to launch an early detection program for DM by using the social media to reach most people.

\section{REFERENCES}

[1] American Diabetes Association Diagnosis and Classification of Diabetes Mellitus Diabetes Care. 2013 Jan; 36(Suppl 1): S67-S74. Published online 2012 Dec 10. Doi: 10.2337/dc13-S067

[2] Abdulfatai B. Olokoba, et al Type 2 Diabetes Mellitus: A Review of Current Trends Oman Med J. 2012 Jul; 27(4): 269-273. Doi: 10.5001/omj.2012.68

[3] Diabetes WHO 30 october 2018 accessed at 21 dec. 2019.

[4] Aastha Chawla, et al Microvasular and macrovascular complications in diabetes mellitus: Distinct or continuum? Indian J Endocrinol Metab. 2016 Jul-Aug; 20(4): 546551. Doi: $10.4103 / 2230-8210.183480$

[5] Abbas Mansour, Meelad Imad Al-Jazairi Cutoff Values for Anthropometric Variables That Confer Increased Risk of Type 2 Diabetes Mellitus and Hypertension in Iraq Archives of Medical Research 38(2):253-8 - March 2007 DOI: 10.1016/j.arcmed.2006.09.014 - Source: PubMed
[6] Mohammad Badran and Ismail Laher *Type II Diabetes Mellitus in Arabic-Speaking Countries Int J Endocrinol. 2012; 2012: 902873. Published online 2012 Jul 18. Doi: $10.1155 / 2012 / 902873$

[7] Hubert Kolb and Stephan Martin Environmental/lifestyle factors in the pathogenesis and prevention of type 2 diabetes BMC Med. 2017; 15: 131. Published online 2017 Jul 19. Doi: 10.1186/s12916-017-0901-x

[8] Silke Feller, ${ }^{1}$ Heiner Boeing, Tobias Pischon, Body Mass Index, Waist Circumference, and the Risk of Type 2 Diabetes Mellitus Dtsch Arztebl Int. 2010 Jul; 107(26): 470-476. Doi: 10.3238/arztebl.2010.0470

[9] Mohammad Fareed et al Life Style Related Risk Factors of Type 2 Diabetes Mellitus and Its Increased Prevalence in Saudi Arabia: A Brief Review International Journal of Medical Research \& Health Sciences, 2017, 6(3): 125132

[10] Ian H. de Boer et al Diabetes and Hypertension: A Position Statement by the American Diabetes Association Diabetes Care 2017 Sep; 40(9): 1273-1284. https://doi.org/10.2337/dci17-0026

[11] RA Scott, et al The link between Family History and risk of Type 2 Diabetes is Not Explained by Anthropometric, Lifestyle or Genetic Risk Factors: the EPIC-InterAct Study Diabetologia. 2013 Jan; 56(1): 60-69. Published online 2012 Sep 28. doi: 10.1007/s00125-012-2715-x

[12] Antonio Bernabe-Ortiz Diagnostic accuracy of the Finnish Diabetes Risk Score (FINDRISC) for undiagnosed T2DM in Peruvian population Prim Care Diabetes. 2018 Dec; 12(6): 517-525. Doi: 10.1016/j.pcd.2018.07.015

[13] Ahmad Alghadir et al Diabetes risk 10 years forecast in the capital of Saudi Arabia: Canadian Diabetes Risk Assessment Questionnaire (CANRISK) perspective Biomedical Research (2014) Volume 25, Issue 1

[14] Macleods Clinical Examination 14th Edition, chapter Body habitus and nutrition, page 29.

[15] https://www.google.com/amp/s/stepfeed.com/a $\mathrm{mp} /$ arab-countries-ranked-by-obesity-levelsamong-adults-6718 Arab countries ranked by obesity levels among adults.

[16] https://www.ncbi.nlm.nih.gov/pmc/articles/PM C4687781/risk_assessment score for screening diabetes mellitus among omani adults, a research done by Melba S DSouza, Anandhi Amirtharaj and Samira Maroof in 2013.

[17] https://www.ncbi.nlm.nih.gov/pmc/articles/PM C5429959/ diabetic risk score in a young student population in Jordan, a research done 
by Abdel_Ellah Al-Shudifat, Amjad AlShudifat and Asgeir Johannessen in 2017

[18] https://www.amhsr.org/articles/finnishdiabetic-risk-score-a-tool-for-predicting-riskof-undiagnosed-type-2-diabetes-mellitus- 3699.html Finnish Diabetic Risk Score: a tool for predicting risk of undiagnosed type 2 diabetes mellitus, a research done in India by Sheikh Mohammed Saleem , S. Muhammad Salim Khan and Shah Sumaya Jan in 2017

Citation: Mayasah A. Sadiq, Alaa A.Salih. Diabetes Risk Assessment among Adult Men in Baghdad City Using Finnish Diabetes Risk Score (FINDRISC). ARC Journal of Diabetes and Endocrinology. 2020; 6(1):31-37. DOI:https://doi.org/10.20431/2455-5983.0601005.

Copyright: (C) 2020 Authors. This is an open-access article distributed under the terms of the Creative Commons Attribution License, which permits unrestricted use, distribution, and reproduction in any medium, provided the original author and source are credited. 